\title{
OPINIONS ABOUT ALLOTTING STRAINS ON THE LAYERS OF A LAMINATED MONOLITH COMPOSITE
}

\author{
RADU IATAN ${ }^{1 *}$, FLORESCU PAVEL ${ }^{1}$, ENĂCHESCU GEORGIANA LUMINIŢA ${ }^{1}$, \\ GHEORGHITTA TOMESCU ${ }^{2}$
}

\author{
${ }^{1}$ Department Equipments for Industrial Processes, University POLITEHNICA of \\ Bucharest, Spaliul Independenţei no. 313, sector 6, Bucharest, Romania \\ ${ }^{2}$ Uzina de Utilaj Petrolier Târgoviște, Romania
}

\begin{abstract}
A previous paper stated the method of determination of the neutral surface of a composite monolithic, laminate composite, organizing some of the component layers, go to the method of distribution of tasks developed in one given case. This regard illustrates several possible options of which results can enable a proper assessment of the maximum strains and alignment layers, ensuring a maximum lifting capacity. The study can be developed to optimize the organization of layers, depending on the practical purpose of using the composite structure (mechanical, thermal and / or sound).
\end{abstract}

Keywords: laminated composite, sectional loads, mechanical and thermal strains

\section{INTRODUCTION}

The minimum consumption of building materials in mechanical structures, usually, but even more in the equipment of great burden, such as those in the process industries, represent a special interest both for the researchers in the field, and for manufacturers and users. Substances are present here, in general, with high working parameters (pressures, temperatures) and high chemical and / or mechanical aggressiveness. These aspects are to be taken into consideration since the projection, in different stages of their work, as when in operation, for metallic materials as well as for composite materials [1-9]. In addition to fulfilling the safety of technical regulations, the authors respond responsibly with regard to the general or specific costs as well [10-11]. It was a key reason for which in a previous work of the authors [12] it was studied the method of determining the neutral position of the surface of a laminated composite, generally with non-symmetrical alignment or a symmetrical (mirrored) one. In this case the sharing variants of loads allotted to component layers are exposed, for static or dynamic applications [13-16]. Such an analysis allows finding, finally, the effective strains developed in layers, and the possibility of comparing the maximum tensions / resistances, to adopt a reasoned decision for the studied case.

Developing the study of the presence of the outside strains on a monolithic laminated board, in this paper, we consider the following aspects:

- it is accepted as known the position of a neutral surface of a board with a given structure, geometric and material;

- accepting the conditions of existence of the same specific linear deformation for all layers, these will be subjected to proportional loads with axial rigidities in longitudinal and transverse direction; the analysis takes into account a constant thickness of each layer, and thus, the same cross-sectional area; the longitudinal elasticity modules and the rigidities of the layers are accepted constant throughout the thickness of the layer concerned;

\footnotetext{
*Corresponding author, email: $\underline{\mathrm{r} \text { iatan@yahoo.com }}$

(C) 2016 Alma Mater Publishing House
} 
- considering the same spins of the layers under the action of uniform bending moments, accepting the position of the neutral surface or not, based on the values attributed to each layer, the expressions of the corresponding tensions are deducted: it proposes three assessment alternatives of the strains developed;

- the same spins are under consideration when allotting the unitary moments of twisting on the layers of a composite, namely to establish formulas for determining the torsional tensions which overlap with the other values of the strains, of a different nature, under the request of an elastic global strain;

- establishing the methodology for allotting the uniform shearing forces in the plans layers and the normal one to their neutral surfaces.

\section{THE DISTRIBUTION OF AN AXIAL FORCE ON A LAMINAE/LAYERS OF A LAYERED COMPOSITE}

It is considered a longitudinal or transverse total force that can develop strain of stretching or compression, irrespective of the position of the neutral surface of the composite in the following (Figure 1). The force in question may be allotted in proportion, considering the same values of the specific linear strains of all laminae. If a board is loaded biaxially it is considered the following expressions:

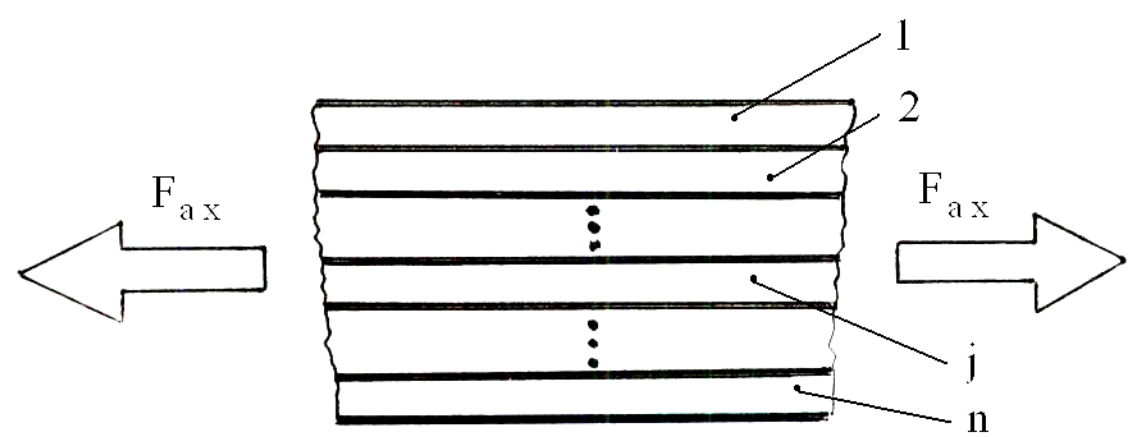

Fig. 1. The distribution of unidirectional force on the strata of the composite.

- Along the axis $O x$ (equation (1)):

$$
\begin{aligned}
& \varepsilon_{x}=F_{x 1} /\left(E_{x 1} \cdot A_{x 1}\right)=F_{x 2} /\left(E_{x 2} \cdot A_{x 2}\right)=\cdots=F_{x j} /\left(E_{x j} \cdot A_{x j}\right)=\cdots= \\
& =F_{x n} /\left(E_{x n} \cdot A_{x n}\right)=\sum_{j=1}^{n} F_{x j} / \sum_{j=1}^{n} E_{x j} \cdot A_{x j}=F_{a x} / \sum_{j=1}^{n} E_{x j} \cdot A_{x j},
\end{aligned}
$$

in which case the distributed forces on the component layers have the relationships (equation (2)):

$$
\begin{aligned}
& F_{x 1}=\left[E_{x 1} \cdot A_{x 1} /\left(\sum_{j=1}^{n} E_{x j} \cdot A_{x j}\right)\right] \cdot F_{a x} ; F_{x 2}=E_{x 2} \cdot A_{x 2} /\left(\sum_{j=1}^{n} E_{x j} \cdot A_{x j}\right) \cdot F_{a x} ; \ldots . . \\
& \ldots F_{x j}=E_{x j} \cdot A_{x j} /\left(\sum_{j=1}^{n} E_{x j} \cdot A_{x j}\right) \cdot F_{a x} ; \ldots F_{x n}=E_{x n} \cdot A_{x n} /\left(\sum_{j=1}^{n} E_{x j} \cdot A_{x j}\right) \cdot F_{a x} \cdot(2)
\end{aligned}
$$

Therefore, the normal strains created in each layer along the axis is determined with the relationships (equation (3)): 


$$
\begin{gathered}
\sigma_{x 1}=\left[E_{x 1} /\left(\sum_{j=1}^{n} E_{x j} \cdot A_{x j}\right)\right] \cdot F_{a x} ; \quad \sigma_{x 2}=\left[E_{x 2} /\left(\sum_{j=1}^{n} E_{x j} \cdot A_{x j}\right)\right] \cdot F_{a x} ; \ldots \\
\sigma_{x j}=\left[E_{x j} /\left(\sum_{j=1}^{n} E_{x j} \cdot A_{x j}\right)\right] \cdot F_{a x} ; \ldots \sigma_{x n}=\left[E_{x n} /\left(\sum_{j=1}^{n} E_{x j} \cdot A_{x j}\right)\right] \cdot F_{a x},
\end{gathered}
$$

which may be of stretching or compressing, as appropriate.

\section{- Along the axis $O y$ (equation (4)):}

The force acting on each layer, along the axis $O y$, produces the specific linear deformation:

$$
\begin{aligned}
\varepsilon_{y} & =F_{y 1} /\left(E_{y 1} \cdot A_{y 1}\right)=F_{y 2} /\left(E_{y 2} \cdot A_{y 2}\right)=\cdots=F_{y j} /\left(E_{y j} \cdot A_{y j}\right)=\cdots= \\
& =F_{y n} /\left(E_{y n} \cdot A_{y n}\right)=\sum_{j=1}^{n} F_{y j} / \sum_{j=1}^{n} E_{y j} \cdot A_{y j}=F_{a y} / \sum_{j=1}^{n} E_{y j} \cdot A_{y j},
\end{aligned}
$$

deducting, further, equation (5):

$$
\begin{aligned}
& F_{y 1}=\frac{E_{y 1} \cdot A_{y 1}}{\sum_{j=1}^{n} E_{y j} \cdot A_{y j}} \cdot F_{a y} ; \quad F_{y 2}=\frac{E_{y 2} \cdot A_{y 2}}{\sum_{j=1}^{n} E_{y j} \cdot A_{y j}} \cdot F_{a y} ; \ldots \\
& F_{y j}=\frac{E_{y j} \cdot A_{y j}}{\sum_{j=1}^{n} E_{y j} \cdot A_{y j}} \cdot F_{a y} ; \ldots F_{y n}=\frac{E_{y n} \cdot A_{y n}}{\sum_{j=1}^{n} E_{y j} \cdot A_{y j}} \cdot F_{a y},
\end{aligned}
$$

respectively the normal strains (tension or compression) (equation (6)):

$$
\begin{aligned}
& \sigma_{y 1}=\left[E_{y 1} /\left(\sum_{j=1}^{n} E_{y j} \cdot A_{y j}\right)\right] \cdot F_{a y} ; \quad \sigma_{y 2}=\left[E_{y 2} /\left(\sum_{j=1}^{n} E_{y j} \cdot A_{y j}\right)\right] \cdot F_{a y} ; \ldots \\
& \sigma_{y j}=\left[E_{y j} /\left(\sum_{j=1}^{n} E_{y j} \cdot A_{y j}\right)\right] \cdot F_{a y} ; \ldots \sigma_{y n}=\left[E_{y n} /\left(\sum_{j=1}^{n} E_{y j} \cdot A_{y j}\right)\right] \cdot F_{a y} ;
\end{aligned}
$$

Note: The equivalent modules of the longitudinal elasticity along the axes $O x$, respectively $O y$, have the expressions (equation (7)):

$$
E_{e x}=\sum_{j=1}^{n} E_{x j} \cdot A_{x j} / \sum_{j=1}^{n} A_{x j} ; \quad E_{e y}=\sum_{j=1}^{n} E_{y j} \cdot A_{y j} / \sum_{j=1}^{n} A_{y j} .
$$

In the previous relationships were also noted the (longitudinal) rigidities when streching / compressing the elements noted ' $j$ ', respectively the equivalent (longitudinal) rigidities characteristic of the same type of strain:

\section{- Along the axis $\boldsymbol{O} \boldsymbol{x}$ (equation (8)):}




$$
\mathfrak{R}_{x j}=E_{x j} \cdot A_{x j} ; \quad j \in[1 ; n] ; \quad \Re_{e x n}=\sum_{j=1}^{n}\left(E_{x j} \cdot A_{x j}\right) ;
$$

- Along the axis $O y$ (equation (9)):

$$
\mathfrak{R}_{y j}=E_{y j} \cdot A_{y j} ; j \in[1 ; n] ; \quad \mathfrak{R}_{e y n}=\sum_{j=1}^{n}\left(E_{y j} \cdot A_{y j}\right) .
$$

\section{DISTRIBUTION OF UNIFORM BENDING AND TWISTING MOMENTS ON THE LAMINAE OF A LAYERED COMPOSITE MONOLIT}

\section{A. The distribution of the unitary bending moments}

\section{Variant I}

In terms of the same rotation (curvature) of the surfaces of composite and laminae, knowing the position of the neutral surface $[12,13]$ and the arrow ' $w$ ' of the board, set for different board types and modes of support, strained statically or dynamically [17-21], it derives the following expressions for the uniform bending moments:

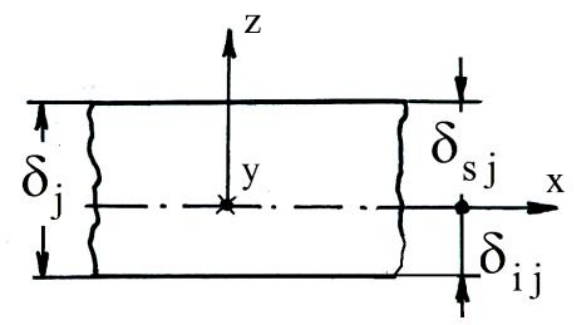

Fig. 2. The neutral position of the surface of the lamina.

\section{- Along the axis $\boldsymbol{O} x$ (equation (10)):}

$$
M_{x j}=\left(D_{11}\right)_{x j} \cdot \chi_{x}+\left(D_{12}\right)_{x j} \cdot \chi_{y}-\left(M_{1 T}\right)_{x j},
$$

where (Figure 2, equations (11)-(13)):

$$
\begin{gathered}
\left(D_{11}\right)_{x j}=E_{x j} \cdot\left(\delta_{s j}^{3}+\delta_{i j}^{3}\right) /\left\{3 \cdot\left[1-\left(v_{x y}\right)_{j} \cdot\left(v_{y x}\right)_{j}\right]\right\} ; \\
\left(D_{12}\right)_{x j}=E_{x j} \cdot\left(v_{y x}\right)_{j} \cdot\left(\delta_{s j}^{3}+\delta_{i j}^{3}\right) /\left\{3 \cdot\left[1-\left(v_{x y}\right)_{j} \cdot\left(v_{y x}\right)_{j}\right]\right\} ; \\
\left(M_{1 T}\right)_{x j}=\frac{1}{2} \cdot \frac{E_{x j} \cdot\left[\alpha_{x j}+\left(v_{y x}\right)_{j} \cdot \alpha_{y j}\right]}{1-\left(v_{x y}\right)_{j} \cdot\left(v_{y x}\right)_{j}} \cdot T_{m j} \cdot\left(\delta_{s j}^{2}-\delta_{i j}^{2}\right) .
\end{gathered}
$$




$$
\sigma_{x j}= \pm 6 \cdot M_{x j} / \delta_{j}^{2} .
$$

- Along the axis $O$ y (Equations (15)-(18)):

$$
\begin{gathered}
M_{y j}=\left(D_{12}\right)_{y j} \cdot \chi_{x}+\left(D_{22}\right)_{y j} \cdot \chi_{y}-\left(M_{2 T}\right)_{y j}, \\
\left(D_{12}\right)_{x j}=\left(D_{12}\right)_{y j} ; \\
\left(D_{22}\right)_{y j}=E_{y j} \cdot\left(\delta_{s j}^{3}+\delta_{i j}^{3}\right) /\left\{3 \cdot\left[1-\left(v_{x y}\right)_{j} \cdot\left(v_{y x}\right)_{j}\right]\right\}= \\
=\left(v_{y x}\right)_{j} \cdot E_{x j} \cdot\left(\delta_{s j}^{3}+\delta_{s j}^{3}\right) /\left\{3 \cdot\left(v_{x y}\right)_{j} \cdot\left[1-\left(v_{x y}\right)_{j} \cdot\left(v_{y x}\right)_{j}\right]\right\} ; \\
\left(M_{2 T}\right)_{y j}=\frac{1}{2} \cdot \frac{E_{y j} \cdot\left[\alpha_{y j}+\left(v_{x y}\right)_{j} \cdot \alpha_{x j}\right]}{1-\left(v_{x y}\right)_{j} \cdot\left(v_{y x}\right)_{j}} \cdot T_{m j} \cdot\left(\delta_{s j}^{2}-\delta_{i j}^{2}\right) .
\end{gathered}
$$

The normal tension, stretching and compressing the two surfaces of the layer have the form (equation (19)):

$$
\sigma_{y j}= \pm 6 \cdot M_{y j} / \delta_{j}^{2} .
$$

Note: In the above it was found the average temperature $T_{m j}$ on the layer thickness.

\section{Variant II}

Considering the position of the neutral surface of the composite board, established based on the above methodology, under the same curvature conditions, uniform bending moments can be distributed as follows:

\section{- Along the axis $O x$ :}

Note: In the following it is considered neutral surface position of the composite [12,13], the distribution of the total bending moment being made based on the rigidity of the assembly and of each layer for the same rotation amount of the la Assuming a layered composite monolith (with layers glued intimately with each other, without slip under the action of external load / loads) and of unique spins, it is expressed the following distribution, for the axis $O x$ (taking into account the flexural rigidity of the layers, with unitary wide and a height $\delta_{j}$ ) [16]:

$$
\begin{aligned}
& M_{x 1} /\left(E_{x 1} \cdot I_{x 1}\right)=M_{x 2} /\left(E_{x 2} \cdot I_{x 2}\right)=\cdots=M_{x j} /\left(E_{x j} \cdot I_{x j}\right)=\cdots= \\
& =M_{x n} /\left(E_{x n} \cdot I_{x n}\right)=\sum_{j=1}^{n} M_{x j} / \sum_{j=1}^{n} E_{x j} \cdot I_{x j}=M_{x} /\left(\sum_{j=1}^{n} E_{x j} \cdot I_{x j}\right),
\end{aligned}
$$

so that (equations (20)-(22)): 


$$
M_{x 1}=\left[E_{x 1} \cdot I_{x 1} /\left(\sum_{j=1}^{n} E_{x j} \cdot I_{x j}\right)\right] \cdot M_{x} ; M_{x 2}=\left[E_{x 2} \cdot I_{x 2} /\left(\sum_{j=1}^{n} E_{x j} \cdot I_{x j}\right)\right] \cdot M_{x} ; \ldots
$$
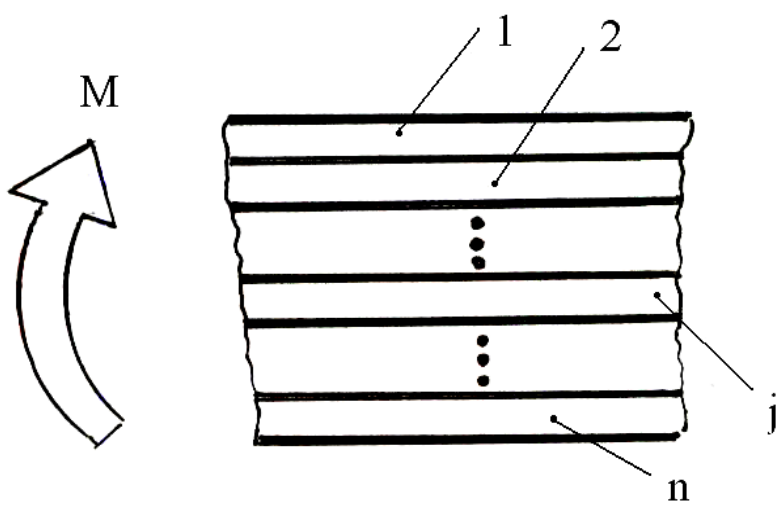

Fig. 3. Distribution of bending moment on the composite layers.

Note: The moments of inertia $I_{x j}$ from the previous relationships are calculated relative to its own axis of symmetry $\left(I_{x_{j}}\right)_{0}$, also taking into account J. Steiner's relationship [22]:

$$
I_{x j}=\left(I_{x j}\right)_{0}+\delta_{j} \cdot d_{x j}^{2}=\delta_{j}^{3} / 12+0,5 \cdot \delta_{j} \cdot d_{x j}^{2}=0,5 \cdot \delta_{j} \cdot\left(\delta_{j}^{2} / 6+d_{x j}^{2}\right) ;
$$

The above equalities can be written by considering the flexural stiffness of the layers (equations (23)-(25)):

$$
\mathfrak{R}_{x 1}=E_{x 1} \cdot I_{x 1} ; \mathfrak{R}_{x 2}=E_{x 2} \cdot I_{x 2} ; \ldots . \mathfrak{R}_{x j}=E_{x j} \cdot I_{x j} ; \ldots \mathfrak{R}_{x n}=E_{x n} \cdot I_{x n} ;
$$

respectively the bending stiffness equivalent to that of the laminated board:

$$
\Re_{x}=\sum_{j=1}^{n} E_{x j} \cdot I_{x j} ;
$$

In the previous relationships with $d_{x j}$ were noted the distances from the neutral surface of the composite to the layer $j$, in case of the appropriate section. Typically, the layers' thicknesses are identical ( $\delta_{x j}=\delta_{y j}=\delta_{j}$ ) in the cross sections of the composite. If the longitudinal elasticity modules are different, the neutral positions of the surfaces in the two cross sections are different, so that the analysis can be done distinctly.

Normal stresses can be evaluated with expressions of the form (14). 
- Along the axis $O \boldsymbol{y}$ (equations (26)-(28)):

$$
\begin{aligned}
& M_{y 1}=\frac{E_{y 1} \cdot I_{y 1}}{\sum_{j=1}^{n} E_{y j} \cdot I_{y j}} \cdot M_{y} ; \quad M_{y 2}=\frac{E_{y 2} \cdot I_{y 2}}{\sum_{j=1}^{n} E_{y j} \cdot I_{y j}} \cdot M_{y} ; \ldots . \\
& M_{y j}=\frac{E_{y j} \cdot I_{y j}}{\sum_{j=1}^{n} E_{y j} \cdot I_{y j}} \cdot M_{y} ; \ldots M_{x n}=\frac{E_{y n} \cdot I_{y n}}{\sum_{j=1}^{n} E_{y j} \cdot I_{y j}} \cdot M_{y} .
\end{aligned}
$$

Note: Given that, in general, the thicknesses of the layer are equal in the directions $O x$ and $O y$, it is inferred that: $I_{x j}=I_{y j}=I_{j}, d_{x j}=d_{y j}=d_{j}$. Since the modules of longitudinal elasticity can be different then, $\mathfrak{R}_{x j} \neq \mathfrak{R}_{y j}$ where:

$$
\mathfrak{R}_{y}=\sum_{j=1}^{n} E_{y j} \cdot I_{y j} \cdot
$$

The tensions developed along the axis $O y$ can be calculated with relations of the form (19).

Note: For each layer of the composite stretching tensions occur on the lower surface, and compression ones on the the upper one, regarding the purpose of the uniform bending time (Figure 3).

In accordance with [16] in the composite layers develop uniform forces and normal proper tensions, according with the intensity of the uniform bending moment, with expressions like:

\section{- Along the axis $O x$}

$$
F_{x j}^{*}=M_{x j} \cdot E_{x j} \cdot \delta_{j} \cdot d_{j} /\left(\sum_{i=1}^{n} E_{x j} \cdot I_{j}\right) ; \quad \sigma_{x j}^{*}=F_{x j}^{*} / \delta_{j} ;
$$

\section{- Along the axis $O y$ :}

$$
F_{y j}^{*}=M_{y j} \cdot E_{y j} \cdot \delta_{j} \cdot d_{j} /\left(\sum_{i=1}^{n} E_{y j} \cdot I_{j}\right) ; \quad \sigma_{y j}^{*}=F_{y j}^{*} / \delta_{j} .
$$

Note: the normal tensions calculated with the equalities (29) and (30) constant on the thickness of the respective layer, add to those developed by uniform bending moments they produce.

\section{Variant III:}

Note: In the following we will consider the position of the neutral composite laminated surface - Figure 4 located within the pale of the element $j$, characterized by the quotas $\delta_{s c}$ and $\delta_{i c}$ of the board with a total thickness $\delta_{c}$. The following inequalities are noted (equation (31)): 


$$
\sum_{u=1}^{j-1} \delta_{u} \leq \delta_{s c} \leq \sum_{u=1}^{j} \delta_{u}
$$

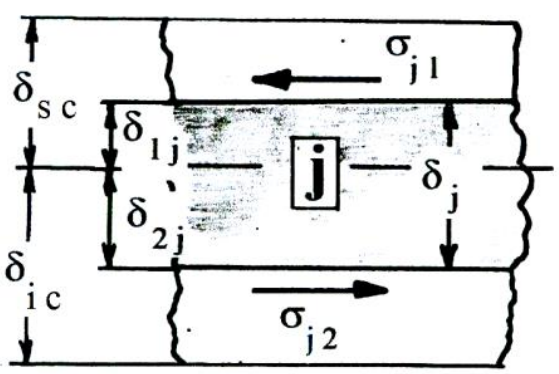

Fig. 4. Loading of the element "j" with normal interfacial tensions.

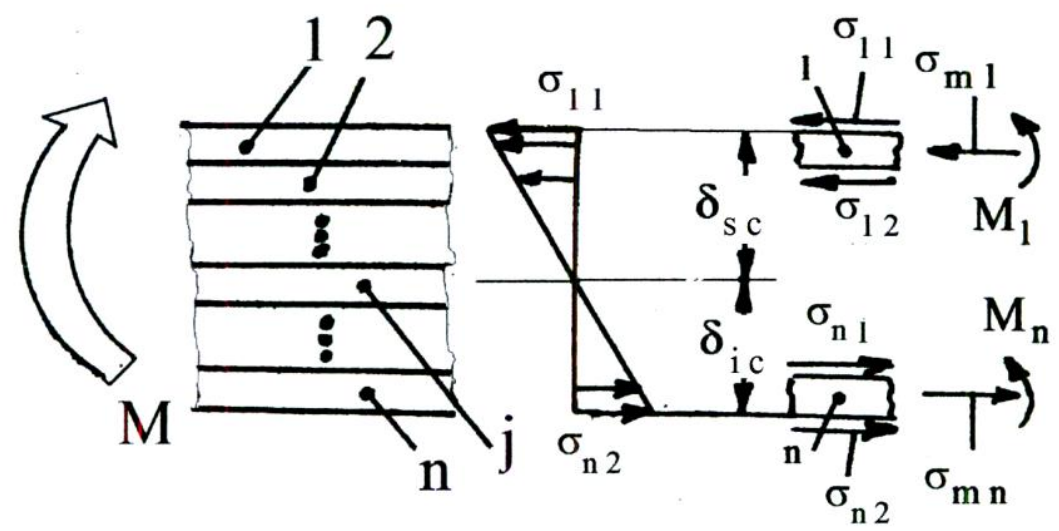

Fig. 5. The distribution of bending moment on the composite layer.

Considering the meaning of the uniform bending moment $M$ in Figure 5, it is accepted the hypothesis of equivalence of this with the distribution of some normal streching tension (width $\delta_{i c}$ ) and of compression (width $\delta_{s c}$ ), resulting in the equality (equations (32)-(38)):

$$
M=\left(\sigma_{11} \cdot \delta_{s c}^{2}+\sigma_{n 2} \cdot \delta_{i c}^{2}\right) / 3
$$

or with regard to the correspondence:

$$
\sigma_{11} / \sigma_{n 2}=\delta_{s c} / \delta_{i c}
$$

getting to:

$$
M=\left[\left(\delta_{s c}^{3}+\delta_{i c}^{3}\right) /\left(3 \cdot \delta_{s c}\right)\right] \cdot \sigma_{11},
$$

respectively: 


$$
\sigma_{11}=-\left[3 \cdot \delta_{s c} /\left(\delta_{s c}^{3}+\delta_{i c}^{3}\right)\right] \cdot M ; \quad \sigma_{n 2}=\left(\delta_{i c} / \delta_{s c}\right) \cdot\left|\sigma_{11}\right| \cdot
$$

Note: in the equality (33) it was not taken into account the sign of the tensions involved in the equality.

Based on the corresponding triangles congruence the following expressions are deducted for the tensions developed at the interfaces among the layers of the composite, written as:

$$
\begin{aligned}
& \sigma_{12}=\sigma_{21}=-\left(1-\delta_{1} / \delta_{s c}\right) \cdot \sigma_{11}=-\left(1-\delta_{1} / \delta_{s c}\right) \cdot\left[3 \cdot \delta_{s c} /\left(\delta_{s c}^{3}+\delta_{i c}^{3}\right)\right] \cdot M \\
& \sigma_{22}=\sigma_{31}=-\left[1-\left(\sum_{u=1}^{2} \delta_{u}\right) / \delta_{s c}\right] \cdot \sigma_{11}= \\
& =-\left[1-\left(\sum_{u=1}^{2} \delta_{u}\right) / \delta_{s c}\right] \cdot\left[3 \cdot \delta_{s c} /\left(\delta_{s c}^{3}+\delta_{i c}^{3}\right)\right] \cdot M \text {; } \\
& \sigma_{p 2}=\sigma_{(p+1) 1}=-\left[1-\left(\sum_{u=1}^{p} \delta_{u}\right) / \delta_{s c}\right] \cdot \sigma_{11}= \\
& =-\left[1-\left(\sum_{u=1}^{p} \delta_{u}\right) / \delta_{s c}\right] \cdot\left[3 \cdot \delta_{s c} /\left(\delta_{s c}^{3}+\delta_{i c}^{3}\right)\right] \cdot M ; p \in[3 ; j-2] ;
\end{aligned}
$$

The tensions on the inferior side of the element $(j-1)$, namely the upper one of the element $j$, equation (39)

$$
\begin{aligned}
& \sigma_{(j-1) 2}=\sigma_{j 1}=-\left[1-\left(\sum_{u=1}^{j-1} \delta_{u}\right) / \delta_{s c}\right] \cdot \sigma_{11}= \\
= & -\left[1-\left(\sum_{u=1}^{j-1} \delta_{u}\right) / \delta_{s c}\right] \cdot\left[3 \cdot \delta_{s c} /\left(\delta_{s c}^{3}+\delta_{i c}^{3}\right)\right] \cdot M .
\end{aligned}
$$

Note: It is noted from the above equality the possibility of assessing the normal tension developed at the top of the element / layer (the compression one, as referred to above).

Taking into account Figure 4 the following relationships are deducted (equation (40)):

$$
\delta_{1 j}=\delta_{s c}-\sum_{u=1}^{j-1} \delta_{u} ; \quad \delta_{2 j}=\delta_{j}-\left(\delta_{s c}-\sum_{u=1}^{j-1} \delta_{u}\right) .
$$

From the contents of Figures 4 and 5 it is easily set the relationship for the calculation of the tension developed on the lower surface of the element $j$ (equation (41)):

$$
\sigma_{j 2}=\left(\delta_{1 j} / \delta_{2 j}\right) \cdot\left|\sigma_{j 1}\right|
$$


and further ((equations (42) - (45)):

$$
\begin{aligned}
& \sigma_{j 2}=\sigma_{(j+1) 1}=\left(\delta_{1 j} / \delta_{2 j}\right) \cdot\left[1-\left(\sum_{u=1}^{j-1} \delta_{u}\right) / \delta_{s c}\right] \cdot \sigma_{11}= \\
& =\left(\delta_{1 j} / \delta_{2 j}\right) \cdot\left[1-\left(\sum_{u=1}^{j-1} \delta_{u}\right) / \delta_{s c}\right] \cdot\left[3 \cdot \delta_{s c} /\left(\delta_{s c}^{3}+\delta_{i c}^{3}\right)\right] \cdot M \text {. } \\
& \sigma_{(j+2) 2}=\sigma_{(j+3) 1}=\left[\left(\delta_{2 j}+\delta_{j+1}\right) / \delta_{s c}\right] \cdot \sigma_{11}= \\
& =3 \cdot\left[\left(\delta_{2 j}+\delta_{j+1}\right) /\left(\delta_{s c}^{3}+\delta_{i c}^{3}\right)\right] \cdot M \text {; } \\
& \sigma_{k 2}=\sigma_{(k+1) 1}=\left[\left(\delta_{2 j}+\sum_{v=j+1}^{k} \delta_{v}\right) / \delta_{s c}\right] \cdot \sigma_{11}= \\
& =3 \cdot\left[\left(\delta_{2 j}+\sum_{v=j+1}^{k} \delta_{v}\right) /\left(\delta_{s c}^{3}+\delta_{i c}^{3}\right)\right] \cdot M \text {; } \\
& k=[j+3 ; n-1] \\
& \sigma_{(n-1) 2}=\sigma_{n 1} ; \sigma_{n 2}=3 \cdot \delta_{i c} /\left(\delta_{s c}^{3}+\delta_{i c}^{3}\right) \cdot M .
\end{aligned}
$$

Note: The bearing capacity of the composite is accepted when the maximum tension is below the / allowable tension/resistance of the material from which the layer in question is carried out.

\section{B. The distribution of uniform twisting moments}

For a moment (total) twist / torque $M_{T}$ (acting in a plane $x O z$-Figure 6) on a layered composite it is considered the same rotation of all layers so that (equation (46)):

$$
\frac{M_{x y 1}}{\beta \cdot \delta_{1}^{3} \cdot G_{1}}=\frac{M_{x y 2}}{\beta \cdot \delta_{2}^{3} \cdot G_{2}}=\cdots=\frac{M_{x y j}}{\beta \cdot \delta_{j}^{3} \cdot G_{j}}=\cdots=\frac{M_{x y n}}{\beta \cdot \delta_{n}^{3} \cdot G_{n}}=\frac{M_{T}}{\beta \cdot b \cdot \sum_{j=1}^{n} \delta_{j}^{3} \cdot G_{j}},
$$

so that the uniform twisting moments allotted to a layer is denoted by the phrase $j ; j \in[1, n]$ has the expression (equation (47)):

$$
M_{x y j}=\beta \cdot \delta_{j}^{3} \cdot G_{j} /\left(b \cdot \sum_{j=1}^{n} \delta_{j}^{3} \cdot G_{j}\right) \cdot M_{T},
$$

where it was used the coefficient dependent on the geometric simplex $b / \delta_{j}$ in this case accepts the value 0,333 , and $\beta \cdot b \cdot \delta_{j}^{3} \cdot G_{j}$ representing the torsional rigidity of the layer, to which belongs the torsional modulus of elasticity $G_{j}$ [22]. As a result there develops the maximum shear tensions (equation (48)) [22]: 


$$
\tau_{y x_{\text {max }}} \approx 3,0 \cdot M_{x y j} /\left(b \cdot \delta_{j}\right) ; \tau_{z x_{\text {max }}} \approx 2,23 \cdot M_{x y j} /\left(b \cdot \delta_{j}\right) .
$$

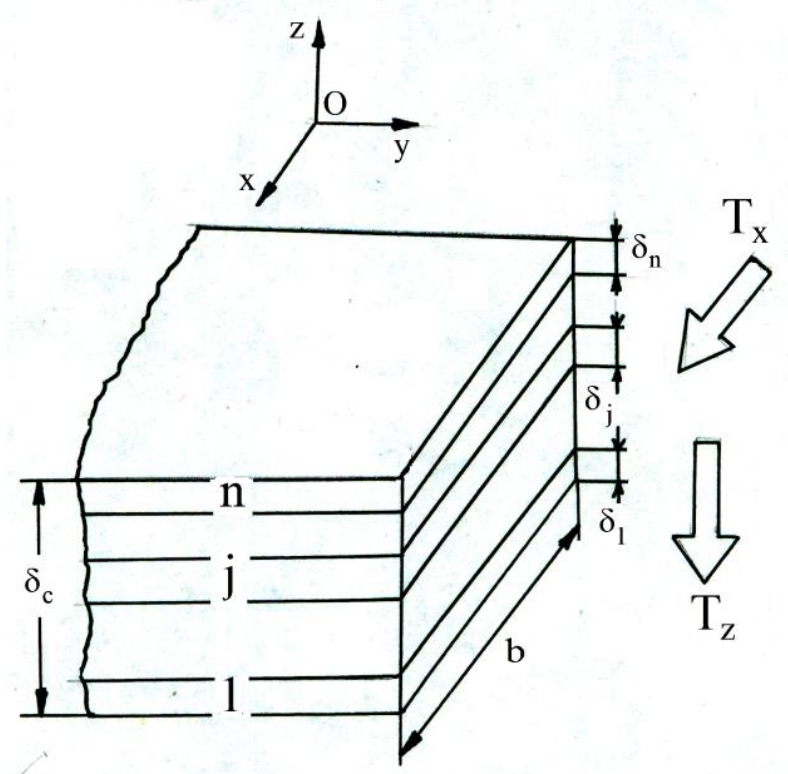

Fig. 6. Distribution of shear forces on the composite layers.

\section{DISTRIBUTION OF CROSS-CUTTING FORCES (SHEAR) ON THE LAMINAE/ LAYERS OF A COMPOSITE}

- Along the axis $O x$ (along the layers of the composite)

\section{Variant I}

Accepting an identical rotation of the layers of the monolithic composite, the unitary force $T_{x}=T_{T x} / b$ acting in a plane $x O z$ (along the axis $O x$ - Figure 6, the uniform force $T_{x}$ is distributed according to the equality (equation (49)) [16]:

$$
\begin{gathered}
T_{1 x} /\left(G_{1} \cdot \delta_{1}\right)=T_{2 x} /\left(G_{2} \cdot \delta_{2}\right)=\cdots \\
=T_{j x} /\left(G_{j} \cdot \delta_{j}\right)=\cdots=T_{n x} /\left(G_{n} \cdot \delta_{n}\right)==_{x} /\left[\sum_{j=1}^{n}\left(G_{j} \cdot \delta_{j}\right)\right],
\end{gathered}
$$

where $G_{j}$ is the modulus of transverse (shear) elasticity of the element / layer $j$ (Figure 6) ( $j \in[1, \cdots, n] ; \delta_{j}$-the thickness of the element $j$. From the equalities (49) follow easily the uniform forces distributed in each layer: (equation (50)).

$$
T_{j x}=T_{x} \cdot G_{j} \cdot \delta_{j} /\left[\sum_{j=1}^{n}\left(G_{j} \cdot \delta_{j}\right)\right],
$$


respectively the equivalent model of cross-elasticity of the composite (equation (51)) [16]:

$$
G_{e c}=\left[\sum_{j=1}^{n} G_{j} \cdot \delta_{j}\right] /\left(\sum_{j=1}^{n} \delta_{j}\right) .
$$

On the basis of the above shear strains can be evaluated from each layer of the composite, with a uniform distribution over the entire cross-sectional area (situated in the plane $x O z$ - Figure 6, equation (52)):

$$
\tau_{j x}=T_{j x} / \delta_{j} ; \quad j \in[1, n] .
$$

\section{Variant II}

The paper [16] considering the distribution of a total cutting / (shear) force in a plane $x O z$ (Figure 6) presents the following calculation relation [D. I. Juravski's formula (1821-1891)] of shear tensions along the dimension / width $b$ with a maximum value in the middle of it (equation (53)):

$$
\tau_{j x}^{*}=\frac{3}{2} \cdot \frac{T_{T x}}{b \cdot \delta_{j}} \cdot \frac{G_{j} \cdot \delta_{j}}{\sum_{j=1}^{n} G_{j} \cdot \delta_{j}}=\frac{3}{2} \cdot \frac{T_{x}}{\delta_{j}} \cdot \frac{G_{j} \cdot \delta_{j}}{\sum_{j=1}^{n} G_{j} \cdot \delta_{j}}=\frac{3}{2} \cdot \frac{T_{x j}}{\delta_{j}},
$$

where it was appealed to the previous notations. It easily appears that $\tau_{j x}^{*}=1,5 \cdot \tau_{j x}$. For a well argued study it is recommended comparing the results offered by earlier formulas to take an appropriate decision to the case and ensure the normal functioning of the structure analyzed.

- $\underline{\text { Along the axis }} O y$ (in a transverse direction to the layers of the composite)

For a composite of a sandwich type ( with three layers) paper [16] gives the following methodology for evaluating the maximum shear strains at the interfaces between the outer layers $\tau_{12}$ and $\tau_{23}$ respectively the one from the middle layer, under the action of a total force oriented along the axis $O z$ (Figure 6, equation (54)).

$$
\begin{gathered}
\tau_{12}=T_{T z} \cdot E_{12}^{*} /\left[b \cdot(E \cdot I)_{3}\right] ; \quad \tau_{2}^{*}=T_{T z} \cdot E_{2}^{*} /\left[b \cdot(E \cdot I)_{3}\right] ; \\
\tau_{23}=T_{T z} \cdot E_{23}^{*} /\left[b \cdot(E \cdot I)_{3}\right],
\end{gathered}
$$

in which these measures were used (equation (55)-(57)):

$$
\begin{gathered}
(E \cdot I)_{3}=b \cdot\left[E_{1} \cdot \delta_{1}^{3} / 12+E_{1} \cdot \delta_{1} \cdot\left(\delta_{1} / 2-\delta_{i c}\right)^{2}+E_{2} \cdot \delta_{2}^{3} / 12\right]+ \\
+b \cdot\left[E_{2} \cdot \delta_{2} \cdot\left(\delta_{1}+\delta_{2} / 2-\delta_{i c}\right)^{2}+E_{3} \cdot \delta_{3}^{3} / 12+E_{3} \cdot \delta_{3} \cdot\left(\delta_{1}+\delta_{2}+\delta_{3} / 2-\delta_{i c}\right)^{2}\right] \\
E_{12}^{*}=b \cdot E_{1} \cdot \delta_{1} \cdot\left(\delta_{i c}-\delta_{1} / 2\right) ; E_{23}^{*}=b \cdot E_{3} \cdot \delta_{3} \cdot\left(\delta_{1}+\delta_{2}+\delta_{3} / 2-\delta_{i c}\right)
\end{gathered}
$$




$$
E_{2}^{*}=b \cdot\left[E_{2} \cdot\left(\delta_{1}+\delta_{2}+\delta_{i c}\right)^{2} / 4+E_{3} \cdot \delta_{3} \cdot\left(\delta_{1}+\delta_{2}+\delta_{3} / 2-\delta_{i c}\right)\right]
$$

Note: The values of shear strains, determined by the equalities (52) are inscribed on a parabolic graph [16].

If it is found that $E_{2} \cdot \delta_{2}\left\langle\left\langle E_{1} \cdot \delta_{1}\right.\right.$ and $E_{2} \cdot \delta_{2}\left\langle\left\langle E_{3} \cdot \delta_{3}\right.\right.$, the shear strain is constant over the entire thickness of the middle layer of the composite, and equal to the values in the areas of separation of the outer layers, so that (equation (58)) [16]:

$$
\tau_{12}^{*} \approx \tau_{2}^{*} \approx \tau_{23}^{*}=2 \cdot T_{T z} /\left[b \cdot\left(\delta_{1}+2 \cdot \delta_{2}+\delta_{3}\right)\right] .
$$

Other notations:

$A_{x j}, A_{y j}-$ cross-sectional area along the axis $O x$ or $O y$, corresponding to the layer $j(j=1 \ldots n)$; $D_{11}, D_{12}, D_{22}$-flexural rigidity; $E_{x j}, E_{y j}$ - modules of longitudinal elasticity of the layers $j$, along two reference axes $F_{x j}, F_{y j}-$; the forces spread across the layers, along the axes of reference $I_{x j}, I_{y j}-$; the moments of inertia of the rectangular sections with width and height equal to the current layer unit $j ; M_{x j}, M_{y j}-$ uniform bending moments relative to and axes $O x$ and $O y ; T_{m j}$ - the average temperature on the thickness of the composite; $w$ - the arrow of the board $\left(v_{x_{y}}\right)_{j},\left(v_{y_{x}}\right)_{j}-;$ the transverse contraction coefficient characteristics of the layer $j ; O x$ and $O y ; \delta_{j}$-the thickness of the layer $j$; $\delta_{j}, \delta_{i j}, \delta_{s j}-$ the thickness of the layer $j$, respectively the distances measured of the neutral surface of the lamina $\delta_{c}, \delta_{i c}, \delta_{s c}-;$ the thickness of a laminated composite respectively the distances measured from the outer surfaces to the characteristic neutral surface; $\varepsilon_{x}, \varepsilon_{y}$ - Specific linear deformations along the axes of reference considered $\Re_{x j}, \Re_{y j}-$; the longitudinal stiffness of the layer $j$ along the axis $O x$, respectively $O y ; \mathfrak{R}_{e x n}, \mathfrak{R}_{e_{y} n}$-the longitudinal stiffness equivalent of the monolithic laminated board; $\chi_{x}=-\left(\partial^{2} w / \partial x^{2}\right), \chi_{y}=-\left(\partial^{2} w / \partial y^{2}\right)-$ the curves of the board along the axes $O x$ and $O y$.

\section{CONCLUSIONS}

Expanding the study determining the neutral position of the surface of a monolithic layered composite, in the contents of the present work it is going to be shown the methods of allotting the uniform shear forces or the normal ones, respectively of the uniform bending or twisting moments. As noted in the analysis presented above, it is taken into account some working hypothesis, as the same specific linear strains, respectively spins, of each layer, in accordance with the composite itself. Depending on the types of plane boards, of various external loads and modes of support to their specific contours, it is determined the normal uniform forces or the uniform bending and twisting moments. Further, the form stability of the board itself can be analyzed, or of the single layers, as well as the influences manifested. The carrying capacity of the layers, respectively of the intrinsic board is determined by the maximum allowable strain values compared with the allowable values, or the structural stability. It is noted that based on the results found, one may move to a proper organization of the layers or to an optimization imposed by the technical and economic nature.

\section{REFERENCES}

[1] Iatan, I.R., Turcu, S., Asupra optimizării construcţiei rezervoarelor metalice cu lobi cilindrici, Buletinul Institutului Politehnic din Bucureşti, vol. 36, no. 1, 1974, p. 67 - 76.

[2] Li, Y.S., Iatan, I.R., Optimizarea construcției recipientelor cilindrice solicitate la presiune exterioară laterală, Revista de Chimie, vol. 34, no. 7, 1983, p. 646 - 652. 
[3] Iatan, I.R., Alămoreanu, E., Chiriţă, R., Optimizarea constructivă şi poziţională a urechilor utilajelor transportate, Buletinul Universităţii Petrol - Gaze din Ploieşti, vol. XLVIII - L (1995 - 1998), no. 8, 1998, p. $153-158$.

[4] Muc, A., Muc, W.M., An evolution strategy in structural optimization problems for plates and shells, Composite Structures, vol. 94, 2012, p. $1461-1470$.

[5] Francescato, P., Gillet, A., Leh, D., Saffré, P., Comparison of optimal design methods for type 3 high pressure storage tanks, Composite Structures, vol. 94, 2012, p. 2087 - 2096.

[6] Burczyński, T., Szczepanik, M., Intelligent optimal design of spatial structures, Computers and Structures, vol. 127, 2013, p. $102-115$.

[7] Chichernea, F., Optimizarea proiectării utilajelor utilizând ingineria valorii, Buletinul AGIR, no. 2, 2013 , p. $29-38$.

[8] Hyder, J.M., Asif, M., Optimization of location and size of opening in a pressure vesel cylinder using ANSYS, Engineering Failure Analxsis, vol. 15, 2008, p. 1 - 19.

[9] Jafari, S., Hojjati, H.M., Fathi, A., Classical and modern optimization methods in minim weight design of elastic rotating disk with variable thicness and density, International Journal of Pressure Vessels and Piping, vol. 92,2012, p. $41-47$.

[10] Fedghouche, F., Tilonine, B., Minimum cost desgn of reinforced concrete T - beams at ultimate loads using Eurocode 2, Engineering Structures, vol. 42, 2012, p. 43 - 50.

[11] Zlender, B., Kravanja, S., Cost optimization of the underground gas storage, Engineering Structures, vol. 33,2011 , p. $2554-2562$

[12] Iatan, I.R., Enăchescu, G.L., Florescu. Gh., On a method for determining the neutral surface on the laminated monolith composites, Journal of Engineering Studies and Research, 2016 (article in press).

[13] Eltaher, A.M., Alshorbagy. E.A., Mahmoud. F.F., Determination of neutral axis position and its effect on natural frecquencies of functionally graded macro/nanobeams, Composite Structures, vol. 99, 2013, p. 193 201.

[14] Enăchescu, G.L.uminiţa, Cercetări teoretice şi experimentale privind solicitări termice în plăci plane din composite stratificate, aflate în structura echipamentelor pentru procese industriale, Teză de doctorat, Universitatea Politehnica din Bucureşti, 2013.

[15] Ogibalov, M.P., Gribanov, F.V., Termoustoicivosti plastin i obolociek, Izd. Moskovskogo Universiteta, Moskva, 1968.

[16]Aerospatiale - Composite stress manual, MTS 006 Iss.B, 1999.

[17] Mazilu, P., Ţopa, N., Ieremia, M., Teoria şi calculul plăcilor ortotrope, Eduitura Tehnică, Bucureşti, 1983.

[18] Mbakogu, C.F., Pavlović, N.M., Bending of clamped orthotropic rectangular plates a variational symbolic solution, Computers and Structures, vol. 77, 2004, p. 117 - 128.

[19] Viktor, A., Isak, B., Evaluation and optimization of orthotropic sandwich plate systems with regard to global deflection: Finite element simulation and analytical evaluation, Thesis, Chalmers University of Technology, Göteborg, Swedwn, 2012 (http://publications.lib.chalmers.se/records/fulltext/163474.pdf 03.08.15).

[20] Broughton, R.W., Crocker, E.L., Urquhart, M.J., Strength of adhesive joints: A parametric study, Project Pajex1 - Report 3, NPL (National Physical Laboratory) Report MATC (Materials Centre) (A) 27, 2011 (http://www.adhesivetoolkit.com/Docu-Data/NPLDocuments/P AJ/PAJex/Reports/PAJex1/PAJex1/Report 4 MATC(A)27.pdf- 23.09.15).

[21] Clarke, J.L (editor), Structural design of polymer composites, EUROCOMP, Design Code and Handbooke, E\&FN SPON, London, England, 1996.

[22] Buzdugan, Gh., Rezistenţa materialelor, Editura Academiei Române, Bucureşti, 1986. 